\title{
USO DE RELATOS ESCRITOS COMO INSTRUMENTO DE AVALIAÇÃO E INTERVENÇÃO EM ORIENTAÇÃO PROFISSIONAL
}

\author{
THE USE OF SELF-RELATED EXPERIENCE AS \\ AN INSTRUMENT TO PROFESSIONAL GUIDANCE'S \\ EVALUATION AND INTERVENTION
}

\author{
Cynthia Borges de MOURA ${ }^{1}$ \\ Ana Claudia Paranzini SAMPAIO ${ }^{2}$ \\ Mirtes Viviani MENEZES ${ }^{3}$ \\ Lígia Deise RODRIGUES ${ }^{4}$
}

\begin{abstract}
RESUMO
O presente trabalho teve como objetivo descrever a experiência autorelatada de adolescentes que participaram de grupos de Orientação Profissional, quanto aos aspectos em comum da condição de entrada e saída do programa. Foram analisados os relatos escritos de 18 adolescentes com idades variando entre 15 e 17 anos, que participavam de dois grupos de Orientação Profissional numa universidade pública, na condição de pré e pós-orientação. Os resultados mostraram três temas principais abordados na condição de entrada: 1) a dificuldade de decisão; 2) as profissões da infância; 3) a influência dos pais. Na condição de saída, os temas foram: 1) aumento do autoconhecimento e conhecimento da realidade profissional; 2) aprendizagem do processo de tomada de decisão; 3) reconhecimento ao trabalho dos orientadores. A condução e manejo dos programas de Orientação Profissional podem ser aprimorados através da compreensão das experiências de crescimento pessoal que os adolescentes vivenciam nos grupos.
\end{abstract}

Palavras-chave: Orientação Profissional, tomada de decisão, adolescentes.

\footnotetext{
(1) Universidade Estadual de Londrina Centro de Ciências Biológicas/Departamento de Psicologia Geral e Análise do Comportamento - Endereço para correspondência: Campus Universitário Caixa Postal 6001 Londrina/PR Cep: 86051-990 E-mail: cbmoura@conectway.com.br

(2) Universidade Estadual de Londrina.

(3) Universidade Estadual de Londrina.

(4) Universidade Estadual de Londrina.
} 


\begin{abstract}
The aim of this work was to describe the self-related experience of adolescents that participate in of groups of Professional Guidance in relation to the common aspects of the entrance and exit condition of the program. Were analyzed writing reports of 18 adolescents between 15 and 17 years old, who participated of 2 groups of Professional Guidance in a Brazilian public university, on the pre-orientation and post-orientation condition. The results show 3 major themes approached in the pre-orientation condition: 1) the decision's difficulties; 2) the childhood professions; 3) the parent's influence. In the post-orientation condition, the themes were: 1) Increase of selfknowledge and knowledge about the professions; 2) Learning of decision's making process; 3) Grateful for the guidance's work. The conduction and handling of the Professional Guidance's programs can be improved through the comprehension about the experiences that the adolescents share in the groups.
\end{abstract}

Key words: Professional Guidance, decision's making, adolescents.

Vário esforço tem sido feito por vários orientadores e pesquisadores para tentar descrever com mais clareza e objetividade quais são as principais dificuldades dos adolescentes que iniciam um processo de Orientação Profissional. Porque precisam de ajuda para escolher? Que habilidades Ihes faltam? Que respostas precisam ser treinadas? Que tipo de informação eles necessitam? O que está gerando tanta dúvida e incerteza? Estas respostas são importantes para nortear as intervenções que serão propostas para tais adolescentes, sempre visando o máximo de efetividade.

Entretanto, para avaliar se as intervenções propostas foram efetivas, necessita-se também identificar com clareza e objetividade quais foram os principais ganhos obtidos por aqueles que concluíram o processo de Orientação Profissional. O que aprenderam? Em que cresceram? Por que conseguiram restringir suas opções? Por que se sentem, então, mais seguros?

Embora instrumentos de medida possam ser muito úteis para fornecer tais respostas ao orientador, acreditamos que o próprio adolescente tem muito a dizer sobre si mesmo, sua condição inicial, sua experiência de discutir suas dúvidas em um grupo, seu processo de aprendizagem e crescimento com a orientação.
Assim, este artigo apresenta a experiência auto-relatada dos adolescentes sobre sua participação em grupos de Orientação Profissional. Serão analisadas as experiências relativas ao motivo da procura por orientação, a participação nos grupos e os pensamentos e sentimentos relacionados à conclusão do processo. O que os adolescentes sentem, o que aprendem, o que pensam que atrapalha seu caminho e o que os ajuda, e em que acham que continuarão crescendo com o que aprenderam nos grupos, serão focos da análise realizada. Acredita-se que avaliar a experiência de crescimento pessoal dos adolescentes, como fruto de sua participação nos processos de Orientação Profissional, pode ajudar os orientadores a identificarem os pontos críticos em comum dessas experiências e a estarem mais atentos à importância e à influência desses fatores na condução de quaisquer programas de Orientação Profissional com adolescentes.

\section{O RELATO ESCRITO E SEUS USOS EM ORIENTAÇÃO PROFISSIONAL}

Muitas são as estratégias utilizadas em Orientação Profissional (OP). Para cada fase de um processo de orientação há um elenco de 
técnicas e recursos disponíveis para facilitação da discussão dos pontos importantes e conseqüente alcance das metas propostas (Lucchiari, 1993; Giacaglia, 2000). Algumas destas estratégias podem ter dupla função, servindo tanto como instrumento de avaliação inicial ou final quanto como fonte de dados para a intervenção.

Uma das estratégias de dupla função bastante utilizada tanto na modalidade de orientação individual quanto grupal é o relato escrito a partir de uma proposição de auto-avaliação do orientando, de sua situação atual e de suas expectativas quanto ao seu processo de tomada de decisão (Soares, 1987; Moura, 2001).

A escolha profissional, compreendida enquanto um processo que requer boa capacidade de discriminação e análise das variáveis envolvida, deve necessariamente empregar procedimentos que facilitem essa análise e levem à ocorrência da tomada de decisão. Levantar pois tais variáveis é condição sine qua non para a tomada de consciência, que pode ser facilitada via utilização dos relatos escritos como parte da intervenção. Para Levenfus (2002), os relatos escritos, além de propiciarem informações na fase de coleta de dados, também apontam importantes categorias para a compreensão do processo de escolha profissional de cada adolescente.

Os relatos em OP têm sido explorados de várias maneiras: na forma de autobiografias; redações temáticas; exercícios de completar sentenças, etc. Segundo alguns autores como Oaklander (1980) e White \& Epston (1990), a redação, como um meio narrativo, é um instrumento valioso e efetivo para a auto-expressão e autodescoberta. Quando escreve sobre si, o indivíduo entra em contato não apenas com sua história, no sentido de acontecimentos vividos, mas também com sua história em termos de dificuldades, expectativas, interesses, potencialidades, valores, aprendizagens, influências. Para Levenfus \& Nunes (2002), os orientandos devem ficar conscientes das influências sobre sua escolha pois, conhecendo-as, o indivíduo pode utilizá-las de forma positiva e construtiva, selecionando-as e adequando-as aos seus próprios desejos e valores.

Para que uma escolha madura venha a ocorrer, é importante que tais aspectos sejam observados e devidamente considerados pelos adolescentes sob orientação. Uma escolha amadurecida pode ser compreendida, de acordo com Levenfus e Nunes (2002), como aquela fundamentada na análise da realidade pessoal e profissional. Portanto, discriminar as variáveis envolvidas na problemática da escolha, por meio do escrever e relatar, pode constituir também uma condição que motive o empreendimento de ações posteriores necessárias à resolução do problema de decisão.

Os relatos escritos, submetidos à análise de conteúdo, tornam-se um instrumento valioso para o trabalho do orientador, na medida em que evidenciam, pela ocorrência nos diversos relatos, categorias temáticas que ampliam a compreensão acerca da maturidade do grupo para o processo de escolha que enfrentarão.

Dentre os temas mais freqüentes categorizados por autores como Oliveira \& Chakur (1997) e Levenfus \& Nunes (2002), numa condição de entrada num grupo de OP, podem-se citar as dificuldades, os medos e as expectativas, cada qual com uma série de subcategorias, próprias das especificidades de cada um. No que diz respeito às dificuldades, são apontadas a falta de informação sobre características pessoais e profissionais, os vários tipos de influência sentidos, além do próprio estado de indecisão em relação à escolha da profissão. Segundo Levenfus \& Nunes (2002)

[...] é comum que os jovens estejam desinformados. Verifica-se que a exploração profissional desenvolvida pelos jovens é pouco sistemática e pouco planejada intencionalmente. É significativa a falta de informações que o adolescente demonstra tanto acerca de si mesmo, quanto acerca do mundo do trabalho e das profissões em geral. Suas escolhas são 
feitas dentre as profissões que podem observarno meio mais imediato, revelando um comportamento exploratório consideravelmente pobre. (p. 68).

Dentre os vários tipos de influência aparecem, explicitamente ou de forma sutil, a influência familiar, dos veículos de comunicação, do grupo social ao qual o adolescente pertence, dos fatores econômicos, dentre outros, que contribuem para o estado de insegurança e indecisão do adolescente. Os medos normalmente apontados estão relacionados principalmente com a possibilidade de uma escolha errada, que resulte em posterior desistência, e com a elevada concorrência vista em alguns cursos. Já as expectativas estão relacionadas com a preocupação de realizar uma escolha acertada; passar no vestibular; adaptar-se à vida acadêmica; conquistar independência financeira, e realizar-se pessoal e profissionalmente.(Oliveira \& Chakur, 1997; Oliveira, Chakur \& Momma, 1997; Levenfus \& Nunes, 2002). Conforme Oliveira \& Chakur (1997):

[...] é importante observar que todos objetivam ingressar num curso superior a qualquer custo [...]; esperam confirmar alguma opção prévia e buscam apoio da orientação.[...] Sentir bem, gostar de fazer, ser feliz, encontrar-se, são os termos que caracterizam a busca de segurança pessoal e profissional para a maioria dos sujeitos. (p. 90)

Na condição de saída, vêem-se relatos com homogeneidade em termos de satisfação com a orientação recebida; clareza de idéias; expectativas realistas, refletindo um aprendizado em termos de tomada de decisão. Moura (2001) encontrou em seu estudo que, mesmo aqueles adolescentes que não concluem o processo de orientação com uma única opção final, obtêm ganhos em termos de aprendizagem do processo de tomada de decisão. Ao final, observa-se que estes adolescentes realizam análises mais apuradas de suas opções, a partir de critérios pessoais mais consistentes.
Uma maior contribuição dos relatos escritos para o trabalho de orientação profissional poderá ser obtida, quanto maior for a capacidade de exploração dos mesmos por parte do profissional. Ao discorrer sobre o uso de história de vida em trabalhos de orientação profissional, Magalhães (2002) chama a atenção do orientador para as idiossincrasias de cada relato, devendo o mesmo buscar verificar a preocupação central do indivíduo, no que se refere à escolha profissional, e o seu posicionamento diante da situação por ele experienciada. Outro aspecto a ser explorado na utilização dos relatos escritos, além do conteúdo, é a maneira como este é relatado (Polster, 1987), o que pode sinalizar o grau de envolvimento do adolescente com sua própria história no processo.

Olhar para os auto-relatos é, pois, importante não apenas para conhecer um pouco da história do indivíduo e sua dinâmica de funcionamento, mas também para, com as informações obtidas, ajustar o formato da intervenção, dimensionando de maneira mais equilibrada os aspectos a serem trabalhados, tendo sempre como meta final a facilitação do processo de escolha profissional de cada adolescente.

Este artigo tem como objetivo descrever a experiência auto-relatada de adolescentes que participaram de dois grupos de Orientação Profissional, quanto aos aspectos comuns da condição de entrada e saída do mesmo programa e apresentar, a partir dos resultados obtidos, uma discussão sobre a utilidade da estratégia de relato escrito tanto como instrumento de identificação de aspectos relevantes ao processo de OP, quanto como feedback do programa empregado.

\section{MÉTODO}

Os Adolescentes: Participaram desta pesquisa 18 adolescentes com idades entre 15 e 17 anos, sendo 13 do sexo feminino e 05 do sexo masculino, alunos da $2^{\mathrm{a}}$ e $3^{\mathrm{a}}$ série do Ensino Médio, provenientes tanto de escolas 
públicas quanto de particulares. Estes adolescentes procuraram espontaneamente pelo serviço de Orientação Profissional de uma universidade pública e foram distribuídos aleatoriamente em dois grupos: o Grupo A era composto por 10 adolescentes e o Grupo B era composto por 08 adolescentes. Todos os adolescentes, assim como seus pais, assinaram um termo de consentimento de participação na pesquisa, concordando com os procedimentos e com a posterior divulgação dos resultados.

Os Orientadores: A equipe de orientadores era composta por cinco pessoas: quatro estagiárias, alunas dos últimos anos do Curso de Psicologia da universidade onde a pesquisa foi realizada e a docente supervisora. O Grupo A foi atendido por duas alunas que já tinham experiência prévia com atendimento clínico e com Orientação Profissional, enquanto a docente e as demais alunas assistiram a todas as sessões em sala-espelho. O Grupo B foi atendido pelas duas alunas que fizeram o treino observacional em sala-espelho, enquanto a docente e as orientadoras do Grupo A assistiram a todas as sessões em sala-espelho (o procedimento de observação em sala-espelho teve objetivos de pesquisa diferentes dos relatados neste artigo). As supervisões eram realizadas logo após as sessões, e toda a equipe estava presente para discussão e planejamento da condução do grupo, dado que o planejamento estratégico se manteve o mesmo para ambos os grupos, conforme descrito a seguir.

A Intervenção: O programa de Orientação Profissional constou de 08 (oito) sessões estruturadas para discussão da problemática vocacional do adolescente e divididas em três etapas: 1) desenvolvimento do autoconhecimento quanto a interesses e habilidades; 2) informação sobre profissões, cursos, carreira e mercado de trabalho; e 3) apoio ao processo de tomada de decisão (ver programa completo em Moura, 2001). As sessões eram semanais com duração de 02 (duas) horas, sob a coordenação de duas orientadoras estagiárias, conforme descrito no item anterior.
A Análise dos Relatos Escritos: $\mathrm{Na}$ primeira e na última sessão solicitou-se aos adolescentes que realizassem uma autoavaliação de sua condição atual no momento de entrada e saída dos grupos por meio de um relato escrito. Na primeira sessão solicitou-se aos adolescentes que escrevessem sobre a seguinte proposição: "O que me trouxe para o processo de Orientação Profissional". Solicitava-se, assim, a exposição de suas vivências, sobre o que pensavam em ser quando crianças, o que atualmente os pais querem que sejam, quais suas expectativas em relação à Orientação, quais as dificuldades que estão tendo para decidir e como esperam resolver a situação de decisão. Na última sessão solicitou-se o relato a partir da proposição "Em que cresci com este grupo e em que acho que ainda poderei crescer", buscando-se assim avaliar o que cada um vivenciou como produtivo para seu crescimento quanto ao processo de tomada de decisão. Ambos os relatos visavam promover uma reflexão específica sobre pontos considerados relevantes para a escolha profissional e a trajetória vocacional/ocupacional. Visavam também proporcionar a livre expressão de idéias, e vivências dos participantes em relação à experiência de solicitar e obter auxílio de um grupo de orientação.

\section{RESULTADOS}

\section{Avaliação dos adolescentes quanto à sua experiência de entrada no grupo}

A avaliação que os participantes realizaram de sua condição de entrada nos grupos foi moldada dentro de alguns parâmetros relativamente amplos que se considerava importante para reflexão posterior, dado que esta estratégia também teve função de intervenção inicial nos grupos. Apesar de ter sido uma reflexão dirigida, observa-se que os adolescentes expressaram muitas de suas vivências pessoais, angústias e preocupações quanto à escolha profissional. Retiramos dos relatos escritos os aspectos e 
vivências apontados por eles como mais marcantes e significativos quanto a cada um dos aspectos solicitados. A metodologia de análise empregada foi a proposta por Amatuzzi (1996). Observou-se que, mesmo tendo um parâmetro pré-delimitado, cada adolescente colocou sua experiência individual e sub-temas emergiram em cada tema solicitado. Cada item será apresentado seguido de recortes ilustrativos dos relatos dos próprios adolescentes quanto à sua percepção acerca da questão. Embora os dados apresentados não tenham características confidenciais, os nomes dos adolescentes foram trocados em respeito à privacidade das experiências dos participantes.

$\mathrm{Na}$ Tabela 1 encontra-se um resumo dos temas principais abordados pelos adolescentes e dos sub-temas que emergiram dos relatos da primeira sessão.

Observou-se nos relatos dos adolescentes uma ênfase maior na exposição das dificuldades de decisão (Tema 1). Todos abordaram o tema, falando de suas dúvidas, do que está atrapalhando seu processo de escolha e o que esperam da orientação quanto à resolução destes conflitos. Alguns adolescentes relataram uma dificuldade difusa (Sub-tema 1.1), não sabendo identificar em que área apresentariam um déficit maior a ser suprido pela orientação. Por esta razão, abordaram amplamente seus sentimentos de indecisão, medos e problemas com tomada de decisão em outras áreas da vida. Mesmo quando citam alguns cursos, são inespecíficos e enfatizam o aumento da dúvida ao considerarem várias opções profissionais. Colocam ainda a expectativa clara de que a orientação os auxilie na resolução destes conflitos. Observem-se alguns relatos:

Camila: "Bom, o que me trouxe para o processo de orientação profissional foi porque estou muito confusa a respeito da profissão desejada. Minhas expectativas em relação à Orientação é que ela me ajude passar por este

Tabela 1. Temas e sub-temas derivados dos relatos escritos na condição pré-orientação.

\begin{tabular}{|c|c|c|}
\hline $\begin{array}{l}\text { Tema 1: } \\
\text { Problema de decisão } \\
\text { enfrentado ao deparar } \\
\text { com o momento de } \\
\text { escolha profissional. }\end{array}$ & $\begin{array}{l}\text { Sub-tema 1.1: } \\
\text { Dúvida difusa, medos, inseguranças, falta } \\
\text { generalizada de informação e autoconhe- } \\
\text { cimento. Problemas com tomada de } \\
\text { decisão em outras áreas da vida. Pouca } \\
\text { ou nenhuma pré-seleção de cursos a } \\
\text { serem considerados durante a orien- } \\
\text { tação. }\end{array}$ & $\begin{array}{l}\text { Sub-tema 1.2: } \\
\text { Dúvida mais específica: falta de } \\
\text { informação sobre cursos, áreas de } \\
\text { atuação e mercado de trabalho ou } \\
\text { de conhecimento de caracterís- } \\
\text { ticas pessoais. Relato sobre os } \\
\text { cursos pré-selecionados e dúvi- } \\
\text { das relacionadas que pretendem } \\
\text { dirimir com a orientação. }\end{array}$ \\
\hline $\begin{array}{l}\text { Tema 2: } \\
\text { Profissões da infância: } \\
\text { o que queria ser quan- } \\
\text { do criança. }\end{array}$ & $\begin{array}{l}\text { Sub-tema 2.1: } \\
\text { Profissões idealizadas provávelmente } \\
\text { admiradas e pretendidas por meio de } \\
\text { contato direto com profissionais, contato } \\
\text { indireto por meio da mídia ou ainda de } \\
\text { atividades relacionadas aos interesses } \\
\text { infantis. }\end{array}$ & $\begin{array}{l}\text { Sub-tema 2.2: } \\
\text { Abandono das concepções e } \\
\text { idealizações infantis e análise } \\
\text { consistente das escolhas presen- } \\
\text { tes e preferências atuais. }\end{array}$ \\
\hline $\begin{array}{l}\text { Tema 3: } \\
\text { Influência dos pais } \\
\text { sobre a escolha profis- } \\
\text { sional. }\end{array}$ & \multicolumn{2}{|c|}{$\begin{array}{l}\text { Sub-tema 3.1: } \\
\text { Identificação dos pais como elementos que incentivam a escolha independente } \\
\text { e a realização profissional do filho. Adolescentes descrevem os pais como } \\
\text { incentivadores e apoiadores, que expressam suas opiniões, mas os deixam } \\
\text { relativamente livres para efetuar suas próprias escolhas. }\end{array}$} \\
\hline
\end{tabular}


obstáculo que é a escolha de uma profissão, minha maior dificuldade é de escolher a profissão certa que se identifique mais comigo, espero que eu consiga achar a decisão certa para que meu futuro seja de vitórias, ou seja, que eu consiga me formar em uma profissão que eu goste e que eu me dê bem com ela"..

Ester: "Espero que essa orientação me ajude na escolha da minha profissão, ou que pelo menos tire minhas dúvidas e que me ajude a crescer como pessoa. Na verdade acho que não me identifico com nada, estudar não é pra mim, mas espero ter mais auto-estima e confiança em mim e nas minhas capacidades. Acho que conhecendo um pouco de algumas profissões, posso me identificar com uma, sendo ela a minha escolha".

Carolina: "O que me trouxe para fazer a orientação profissional, é para me ajudar a escolher uma profissão, pois tenho muitas dúvidas sobre o que fazer. Meu medo é de escolher uma profissão, começar a estudar e ver que não era isso o que eu queria, então espero que essa Orientação Profissional me ajude na minha escolha".

Ricardo: "Eu vim para a Orientação para 'eliminar' algumas das minhas idéias a respeito de qual curso escolherei, porque é bom escolher um, só para começar. Minhas dificuldades são muitas pois quando eu vejo que estou me decidindo aparece um interesse em outra área, um dos motivos que acho que é porque eu me interesso muito pelo que eu me dou bem, então cada vez mais eu descubro novos caminhos, eu pretendo decidir-me através do curso que me interesse mais e que melhor se assemelhe comigo".

Juliana: "O que me trouxe para o processo de orientação profissional foi a grande dúvida do que fazer no vestibular e em toda a minha vida. Tenho essa dúvida pois tenho medo de escolher uma profissão e depois me arrepender. [...] Apesar de tantas profissões que eu acho legal, não escolhi um ainda. Quero uma profissão que ganhe bem e que eu goste muito. Espero que com essa orientação eu consiga encontrar essa profissão".

Vanessa: "São várias coisas, primeiro nunca tive um sonho de fazer algum curso quando era criança. Há dois anos atrás pensava em fazer Administração, aí vendo o meu tio como Nutricionista gostei da coisa e aí comecei a ficar confusa sobre o que escolher. Gosto mais de matérias exatas do que as outras por isso fico entre essas matérias. Por isso quando a Dani falou desse curso (a orientação) logo me interessei. Então venho aqui para fazer logo uma escolha exata do que devo escolher e buscar conhecer novas coisa".

Ainda quanto ao problema de decisão enfrentado ao deparar com o momento de escolha profissional (Tema 1), a maioria dos adolescentes foi um pouco mais específica ao escrever sobre sua problemática (Sub-tema 1.2). Os adolescentes que se enquadraram nesta categoria abordaram seu problema de decisão em termos de falta de informação sobre os cursos, áreas de atuação e mercado de trabalho, citaram também a questão da melhoria do autoconhecimento quando falaram a respeito da necessidade de saber sobre sua "identificação" com o curso escolhido. Alguns citaram os cursos que estavam considerando e explicaram, mesmo que superficialmente, suas dúvidas em relação a eles. Outros falaram sobre a importância de integrar o conhecimento de si mesmo com o conhecimento das profissões. Estes aspectos podem ser observados nos relatos abaixo:

Carlos: "Decidi fazer a orientação para poder esclarecer dúvidas em relação a profissões e aonde é ideal cursar cada profissão, então, espero que isso realmente ocorra e todas as novas informações serão, digamos assim, um 'bônus'. Estou tendo dificuldade em unir uma profissão de meu agrado com as perspectivas do mercado trabalhista e espero resolver isso com esse grupo de orientação".

Daniele: "O que me trouxe aqui é não saber exatamente o que se faz na área de ADM, também gostaria de conhecer outros cursos 
antes de opinar nesse curso. Espero poder sair desse curso com uma idéia mais firme na cabeça".

Leonardo: "Acho que isso [a orientação] vai me ajudar e muito na minha escolha profissional, pois estou indeciso. Olha, me adentrei, bem nesse negócio de informática, mais ainda não sei se é realmente o que quero, penso em outras coisas, como Direito e tal. Com a ajuda de vocês orientadoras, espero resolver se isso que estou fazendo (informática) é mesmo o meu forte (minha vocação) ou se é somente fogo de palha mesmo, se tenho que partir para outra coisa, se tenho, ainda não sei muito bem o que devo fazer".

Ananda: "Estou em dúvida entre duas profissões, espero que essa orientação me ajude para eu decidir qual que eu tenho mais afinidade".

Cássia: "Não vi o tempo passar e quando eu vi já estava na época de fazer as inscrições para o vestibular. Por isso eu conversei com algumas pessoas e decidi fazer psicologia, mas não sei se é realmente isso que eu quero. Acho que eu não faço medicina porque eu tenho muito medo de não passar... Com a orientação eu espero poder conhecer melhor os cursos e o campo de trabalho, em especial o de Ed. Física, Psicologia e Medicina que são os que eu estou mais a fim de fazer".

Simone: "Tenho dúvidas sobre o que escolher, porque não sei com o que tenho facilidades ou dificuldades, com a ajuda do programa pretendo me autoconhecer melhor. Quero ter conhecimentos sobre outros cursos, outras áreas, para eu poder saber com qual vou me identificar melhor. Tenho dúvida em três cursos de áreas diferentes, e fico confusa do que mais gosto".

Priscila: "Eu sei mais ou menos das coisas que eu não gosto, mas não consigo definir o que realmente gosto. Eu acho que quero fazer Administração e como o mercado de trabalho está meio difícil pretendo fazer também Engenharia Elétrica, o único problema é que eu estou indecisa se é o que eu realmente gosto de fazer isso e seu eu 'dou conta'. Espero que eu consiga definir as coisas de que realmente gosto para conseguir me encaixar em uma profissão em que eu me sinta bem e realizada".

"O que queria ser quando criança" foi outro tema abordado pelos adolescentes (Tema 2), embora com menor ênfase. Alguns adolescentes citaram as profissões idealizadas da infância (Sub-tema 2.2), provavelmente admiradas e pretendidas por meio do contato direto com profissionais (professor ou pediatra, por exemplo), ou via contato indireto por meio da mídia (paleontólogo, detetive, jogador de futebol) ou ainda por intermédio de atividades adultas que se identificavam com as atividades e interesses infantis (animais = veterinário; escrever no quadro = professora). Observem-se os relatos:

Carlos: "Quando criança queria ser detetive ou 'caçador de ossos de dinossauro' (paleontó$\log 0)$ ".

Ester: "Quando criança pensava em ser professora, porque adorava ensinar meus irmãos e escrever no quadro".

Camila: "(...) quando criança pensava em ser médica na área de pediatria".

Juliana: "Já pensei em ser muitas coisas quando criança, como professora, médica, advogada, engenheira elétrica, alguma coisa na área de educação física, entre outras”.

Rodrigo: "Sempre fui uma pessoa muito indecisa e insegura quanto as minhas escolhas. Quando criança nunca tive uma única escolha ou uma escolha que realmente me agradava. Minhas escolhas iam de jogador de futebol a médico".

Mesmo os adolescentes que citaram profissões idealizadas, relataram abandono das concepções infantis e colocaram-se em condições de analisar as escolhas presentes e as preferências atuais sem a influência de tais fantasias (Sub-tema 2.2). Para o processo de escolha profissional, esta mudança de concepção indica maturidade para a escolha e abre novas possibilidades de análise para opções 
ainda não consideradas, como pode ser observado nos relatos:

Leonardo: "Quando criança pensava em um punhado de coisas, principalmente em coisas que hoje não penso mais, por exemplo, caminhoneiro e outras coisas mais. Mais sempre pensei em mexer com papelada, ou seja, escritório (...)".

Carolina: "E quando eu era criança, eu queria ser professora, mas com o passar do tempo, eu sei que não era isso o que eu queria".

Daniele: "O que eu pensava quando era criança era em ser dentista, mas depois eu vi que o meu forte mesmo é alguma coisa na área que tinha matemática".

André: "Quando criança, já pensava em trabalhar em alguma área que tivesse contato com animais, e então comecei a me interessar por veterinária".

Ananda: "Quando eu era criança pensava em ser muitas coisas, mas o que eu mais queria era ser pediatra, não sei por quê. Mas isso com o tempo foi mudando".

Cássia: "Desde pequena, eu sempre falei que iria fazer Medicina, e me especializar em pediatria, porque sempre gostei muito de criança porém de uns 2 anos pra cá eu comecei a ter dúvidas do que eu realmente deveria fazer. Nesses 2 anos eu já falei que iria fazer Ed. Física, Psicologia, Artes Cênicas, Ciência do Esporte e também Medicina".

Fernanda: "Quando era mais nova vivia falando que iria ser médica, mais tarde mudei de idéia (...)".

Outro tema abordado pelos adolescentes em seus relatos pré-orientação foi a influência dos pais sobre a escolha (Tema 3). Podem-se observar nos relatos abaixo uma maior incidência de adolescentes que identificaram seus pais como elementos que valorizam a escolha independente e a realização profissional do filho (Sub-tema 3.1). Os pais, embora opinem sobre a escolha, parecem deixar o adolescente relativamente livre para efetuar suas próprias escolhas, as quais, na visão dos próprios filhos, procuram incentivar e apoiar:

Carlos: "Meus pais sempre me deram liberdade de escolha, portanto isso deixa minha escolha mais fácil".

Daniele: "Meus pais deixam eu decidir o que eu acho melhor".

Camila: “(...) minha mãe não opina sobre minha profissão, só acha que eu tenho que escolher o que vai ser melhor para mim".

Carolina: "Meus pais dão palpite sobre o que eu deveria fazer, mas não me obrigam a nada, e sei que eles darão apoio para mim, qualquer que seja minha decisão".

Leonardo: "Bom, comecei a me adentrar no ramo da informática e meus pais acham que devo até seguir nesta área, mas não costumam darnenhum palpite".

Ricardo: "A princípio, eu pensava em ser veterinário, que é porque meu pai é, mas meus pais não me pressionam nem exercem muita influência a respeito disso".

Ananda: "Meus pais sempre me apoiaram em relação a que profissão seguir, ou seja, respeitam a minha decisão independentemente se eles gostaram ou não, o que importa pra eles é que eu goste e me realize profissionalmente".

Cássia: "Meus pais me deixam tranqüila para escolher, meus colegas do grupo falam para eu fazer medicina, já a minha turma do colégio e a minha técnica falam para eu fazer Ed. Física porque eu gosto muito de praticar esportes".

Fernanda: "Em relação aos meus pais não tenho problemas pois sei que o curso que eu escolher eles darão a maior força".

Quanto a este tema, apenas dois relatos indicaram um controle familiar um pouco mais coercitivo, embora sutil, pois os adolescentes não relataram sentirem-se pressionados, mas reconheceram que as "opiniões paternas" estavam aumentando os sentimentos de indecisão e dificultando a tomada de decisão. Observe os relatos: 
Vanessa: "Agora este ano meu pai fica fazendo a minha cabeça para que eu faça Educação Física. Apesar de gostar muito de nadar, jogar vôlei, etc., fico confusa pois não sei se vou gostar".

André: "Quando fui ficando mais velho, não tinha outra opção na cabeça a não ser esta [veterinária]. Mas quando entrei no $1^{\circ}$ colegial, meus pais começaram a me indicar outras profissões, e eu fiquei meio confuso".

\section{AVALIAÇÃO DOS ADOLESCENTES QUANTO À SUA EXPERIÊNCIA DE CONCLUSÃO DO PROCESSO}

Ao final da oitava sessão de orientação (última sessão) os participantes realizaram uma avaliação de sua condição de saída dos grupos. Este último relato não teve função explícita de intervenção, pois os aspectos relatados não foram amplamente discutidos. A função principal da estratégia era de conclusão do processo e coleta de dados para a presente análise, realizada posteriormente. Este último relato se caracterizou como uma reflexão menos dirigida do que o relato da primeira sessão, pois a proposição era apenas "Em que crescicom este grupo e em que acho que ainda poderei crescer". Novamente os adolescentes puderam expressar suas vivências pessoais quanto aos aspectos mais significativos ocorridos durante o processo. Cada adolescente colocou sua experiência de participação no grupo e a análise posterior apontou sub-temas para cada tema relatado, conforme sintetizado na Tabela 2 e demonstrado a seguir.

Um tema que se destacou pela freqüência com que ocorreu nos relatos dos participantes foi o aumento do conhecimento de si mesmo e a aquisição de informações profissionais (Tema 1). Os adolescentes relataram que agora conhecem as próprias características, tem mais informação sobre os diversos cursos e carreiras e conseguem integrar melhor tais dados, de forma a sentirem-se agora mais aptos a realizar sua escolha. Os adolescentes que relataram melhora no autoconhecimento enfatizaram uma estratégia utilizada nos grupos que era a

Tabela 2. Temas e sub-temas derivados dos relatos escritos na condição pós-orientação.

\begin{tabular}{|c|c|c|}
\hline $\begin{array}{l}\text { Tema 1: } \\
\text { Aumento do autoco- } \\
\text { nhecimento e conhe- } \\
\text { cimento da realidade } \\
\text { profissional facilitan- } \\
\text { do o processo de es- } \\
\text { colha. }\end{array}$ & $\begin{array}{l}\text { Sub-tema 1.1: } \\
\text { Ênfase no autoconhecimento. Distinção } \\
\text { clara entre o que gosta e não gosta, o } \\
\text { que facilitou a escolha por eliminação } \\
\text { de opções. }\end{array}$ & $\begin{array}{l}\text { Sub-tema 1.2: } \\
\text { Ênfase na informação profis- } \\
\text { sional. Preferência pela estratégia } \\
\text { de entrevista com profis-sionais } \\
\text { como acesso direto à realidade. }\end{array}$ \\
\hline $\begin{array}{l}\text { Tema 2: } \\
\text { Aprendizagem do pro- } \\
\text { cesso de tomada de } \\
\text { decisão e realização } \\
\text { da escolha. }\end{array}$ & $\begin{array}{l}\text { Sub-tema 2.1: } \\
\text { Integração das características pessoais } \\
\text { com as informações profissionais. } \\
\text { Resolução das dúvidas e tomada de } \\
\text { decisão com mais segurança. }\end{array}$ & $\begin{array}{l}\text { Sub-tema 2.2: } \\
\text { Aprendizagem do processo de } \\
\text { tomada de decisão para a } \\
\text { profissão e para a vida. Dissolução } \\
\text { dos medos. Crescimento pessoal } \\
\text { generalizado. }\end{array}$ \\
\hline $\begin{array}{l}\text { Tema 3: } \\
\text { Reconhecimento ao } \\
\text { trabalho efetuado pe- } \\
\text { los orientadores. }\end{array}$ & \multicolumn{2}{|c|}{$\begin{array}{l}\text { Sub-tema 3.1: } \\
\text { Desconfiança inicial com o trabalho. Mudança de sentimento no decorrer } \\
\text { dos encontros. Resultados obtidos atribuídos ao manejo das orientadoras } \\
\text { e às estratégias de grupo utilizadas. }\end{array}$} \\
\hline
\end{tabular}


identificação das "não-preferências e inabilidades", como forma de iniciar o processo de escolha, "eliminando o que você não quer" (Sub-tema 1.1). Isto pareceu ser muito relevante para alguns adolescentes, como mostram os seguintes relatos:

Ananda: "Quando eu entrei no grupo, já tinha mais ou menos uma idéia de qual profissão seguir, é lógico que com muitas dúvidas ainda. No início eu consegui me conhecer um pouco mais, ou seja, saber do que eu gosto e do que eu não gosto também. Foi muito bom isso pra mim".

Cássia: "O grupo me ajudou muito para que eu pudesse decidir qual o caminho [que profissão] seguir. No grupo eu comecei a ver não somente o que eu gostava, e também o que eu não gostava, o que ajudou a eliminar várias opções de cursos".

Daniele: "O grupo serviu muito para mim, pois com as sessões pude me deparar com as altas e baixas características do curso que irei fazer. Com isso percebi do que realmente gosto e não gosto, assim, fui descartando as profissões que na verdade não combinavam comigo".

Vanessa: "Quando comecei entrei com várias dúvidas do que iria fazer, mas o grupo me ajudou a ver melhor os pontos de vista de cada profissão, a discutir e ouvir a opinião de todos e achar a profissão que nem tinha idéia de como era. Aprendi a ver do que gosto ou não de fazer e através disso descartar ou não possibilidades".

Para um outro grupo de adolescentes, o que pareceu ser mais relevante foram as informações proporcionadas pelo programa de orientação (Sub-tema 1.2). Estes adolescentes enfatizaram o quão importante foi para eles conhecer várias profissões e não se deterem apenas naquelas que estavam considerando. É interessante notar como a estratégia de entrevista pessoal com profissionais foi bastante citada e considerada significativa para o processo de tomada de decisão. Alguns relatos nesta direção:

Ananda: “(..) Em seguida me foram apresentadas várias profissões. No começo isso me atrapalhou muito mais em relação a minha escolha, mas aos poucos eu fui conseguindo me concentrar em uma só, através da entrevista que nós fizemos com os profissionais".

Vanessa: “(...) [aprendi] principalmente na hora de entrevistar profissionais que tem uma postura ética e os que não tem. Através dessa entrevista surgiu em mim um interesse que não sabia que existia".

Juliana: "Através das pesquisas, discussões e principalmente da entrevista, percebi que eu realmente gosto e ficaria muito realizada de ser uma matemática. Uma professora de matemática. Essa sempre foi minha matéria preferida, mas nunca tinha me ocorrido a idéia de tornar a minha matéria preferida uma profissão. E a escola sempre foi um lugar onde eu sempre gostei de estar, com pessoas jovens, um lugar alegre, movimentado. Vou gostar muito de dar aulas!".

André: "Me ajudou a ter uma visão mais ampla das profissões que eu tinha interesse. Me conheci melhor, conheci novas áreas de atuação no mercado. Me incentivou a pesquisar novas profissões, a decidir minha profissão".

Daniele: "Ajudou a me posicionar para saber em que ramo de profissão mais me agrada, a saber um pouco mais da minha preferência desde o que vou fazer na faculdade e fora dela quando estiver trabalhando e também me ajudou a informar-me sobre outras profissões".

Ester: "O grupo trouxe para mim uma grande ajuda, pois eu estava super indecisa em relação à profissão que eu iria exercer. No grupo eu conheci profissões que nem sabia que existia e outras que comecei a conhecer melhor. Pode até ser que não tenha escolhido a profissão certa para mim, mas foi o que mais me identifiquei. Com o grupo me aprofundei em algumas profissões e conheci algumas coisas básicas mas que eu não sabia, como por exemplo: o tempo de duração do curso, o salário, e até mesmo outras áreas da mesma profissão. Se eu não tivesse participado desse grupo 
escolheria uma profissão qualquer sem ter conhecimento das outras. O mais interessante foi as entrevistas que fizemos com pessoas já formadas, aprendi muito (...)".

Carolina: "Me ajudou a ter mais conhecimento nas áreas [...] e me ajudou a conhecer mais as profissões, as pesquisas sobre elas, e aumentou meu conhecimento sobre várias profissões, e principalmente nas áreas de meu maior interesse".

Leonardo: "Entrei neste grupo muito indeciso, sem conhecer o que era realmente cada profissão, qual sua renda, o que fazia, muitas coisas em relação ao estudo da tal profissão e coisas mais. Foi muito bom para me esclarecer sobre muitas coisas, dentre as profissões, entre o estudo das profissões, etc".

A aprendizagem do processo de tomada de decisão (Tema 2) pareceu ocorrer para a maioria dos adolescentes. Eles relataram a integração de informações pessoais e profissionais como importante para o amadurecimento da escolha a ser feita (Tema 2.1) e atribuíram às discussões e reflexões realizadas nos grupos a aprendizagem de como fazer escolhas. Alguns ressaltaram a resolução de suas dúvidas e outros enfatizaram que o processo ocorrido nos grupos foi suficiente para levá-los a concluir sua escolha com maior segurança. Tais experiências podem ser observadas nos relatos abaixo:

Carlos: "Vim ao grupo com poucas dúvidas na minha cabeça, mas eram dúvidas que necessitavam de um maior esclarecimento. Ao decorrer dos encontros fui evoluindo de acordo com as novas informações e pensamentos elaborados pelo grupo e por mim. Finalizei diversos dilemas em minha mente com a orientação. Hoje posso ter mais certeza do que eu quero para minha vida, e sempre saberei a maneira correta de tomar uma decisão".

Ricardo: "Durante esse acompanhamento, percebi que tive mais seriedade e firmeza em minhas decisões, descobri como realmente são as profissões de meu interesse e sintetizei minha escolha".
Daniele: "Hoje já tenho a minha decisão para a escolha da profissão que quero prestar no vestibular. Com certeza o curso [orientação] me encaminhou para a decisão correta e me fez crescer e abrir os olhos. Espero que da mesma forma como eu saí realizada deste curso eu entre em uma faculdade e me forme na profissão que desejo".

Camila: "Sobre a profissão aprendi bastante, conheci coisas que eu não imaginava ter no curso, ou seja, matérias e especializações muito atraentes. A orientação me ajudou muito, no começo estava com várias dúvidas, se eu iria conseguir escolher uma profissão, estava muito confusa no começo, mas agora já tenho uma opinião".

Fernanda: "O grupo de apoio me ajudou a esclarecer algumas dúvidas que eu tinha e que me faziam pensar em desistir. O grupo mostrou que as pequenas barreiras vão existir em qualquer lugar e que um empecilho tão pequeno não é suficiente para desistir, é preciso mais que isso. Hoje saio desse grupo de apoio decidida, e sei, ao menos acho que sei, que é realmente medicina que quero prestar e que não vai ser a concorrência nem o esforço que a profissão exige que vai me fazer desistir".

Marina: "Com o grupo tive a oportunidade de observar melhor as minhas característicase onde elas se encaixam. Pude me conhecer melhor. Tive maiores informações sobre as profissões que havia pensado antes. Conheci mais as áreas de atuação de cada uma e pude relacionar o que gosto com as exigências de características que são pedidas em cada curso. Agora posso fazer uma comparação do 'antes e depois', pois tive novas idéias voltadas para o que gosto. Foi muito bom este acompanhamento, pois além da área profissional, tive a oportunidade de me conhecer melhor. Já tenho certeza do que quero e estou procurando conhecer melhor ainda a minha área".

Priscila: "O grupo me ajudou a auto-reconhecer, descobrir a si mesmo é essencialmente importante porque possibilita tomar caminhose decisões que sejam mais fiéis à personalidade 
de cada um. É preciso dar mais importância a algumas coisas e menos a outras como: 'tem algumas coisas que eu gosto nessa profissão e tem algumas coisas que eu não gosto, qual tem mais relevância, as coisas que gosto ou não? Isso pode ser aplicado em todas decisões com várias opções".

Ainda enfatizando a aprendizagem da tomada de decisão, alguns adolescentes relataram a superação de seus medos e melhora na autoconfiança como resultado da participação nos grupos de orientação profissional (Sub-tema 2.2). Seus relatos expressam que a experiência de participação em um grupo de orientação resultou em aprendizagem do processo de tomada de decisão não só para a profissão, mas também para a vida, pois puderam crescer pessoalmente, mudar conceitos e firmar opiniões. Seguem alguns relatos que exemplificam este aspecto:

Vanessa: "Mas foi toda essa experiência que passei com o grupo que me fez decidir por uma coisa que antes não tinha certeza ou como eu disse: 'se eu fosse escolher...' Hoje não penso e nem vou falar assim e nunca vou dizer não gosto sem ter experimentado ou dizer 'já escolhi!', sem ter pensado antes. E tudo isso pelo grupo ter aberto meu caminho e ter escutado a todos".

Cássia: "Quando eu cheguei, tudo o que viesse era lucro, agora eu vi que não é qualquer coisa que eu devo fazer, mesmo que eu tenha que lutar muito para conseguir, como é o caso da medicina, que eu tinha medo de fazer porque é um curso muito concorrido, mas é o que eu gosto, por isso eu tenho que correr atrás dos meus objetivos. E isso, não só agora, na escolha profissional, e sim a vida toda, pois muitos obstáculos vão surgir, e eu terei que analisar tudo que engloba o problema para poder tomar uma decisão. Por isso que o grupo me ajudou (...)".

Juliana: "O grupo me ajudou muito, pois antes eu só pensava em me formar para ter dinheiro e ser independente. O dinheiro falava mais alto. Agora percebi que não é isso que realmente gosto. É claro que o dinheiro é importante, mas agora o vejo como conseqüência do trabalho. Poderei crescer muito mais, pois farei muitas outras pesquisas e entrevistas. $E$ aprendi uma coisa muito importante, que não existe uma escolha errada (...) e isso me faz não ter medo da minha escolha, apesar de achar que escolhi a profissão certa".

Rodrigo: "O meu crescimento no grupo aconteceu, uma vez que, ao pensar que já havia feio minhas escolhas, voltei a ser questionado sobre elas. Com o passar dos momentos críticos, como o vestibular e a opção por outras faculdades, várias outras dúvidas foram surgindo e em seguida respondidas, me fazendo muitas vezes restabelecer conceitos já formados em relação às profissões e escolhas. Hoje nem todas minhas dúvidas foram sanadas, mas carrego comigo uma maior segurança ao tomar decisões sobre meu futuro, tanto quanto ao curso quanto a faculdades".

Leonardo: "E foi também um bom tempo que tirei para pensar realmente no que quero, pois, acho que sozinho, não tiraria este tempo. Foi bom para me autoconhecer também. Não digo que já me decidi pois ainda não realmente, mas espero tomar a decisão em breve. Foi bom tudo o que fizemos nestas oito sessões, e foi muito válido".

Um terceiro tema, embora tímido, por ter aparecido no relato de três adolescentes apenas, se destacou por não se enquadrar nas categorias anteriores. O Tema 3 refere-se à expressão de reconhecimento ao trabalho efetuado pelas orientadoras. Tais adolescentes relataram desconfiança inicial com o trabalho e mudança de sentimento no decorrer dos encontros. Relacionaram ainda os resultados obtidos do manejo das orientadoras e das estratégias de grupo utilizadas (Sub-tema 3.1), como mostram os recortes:

Juliana: "Com certeza os meus objetivos com o grupo foram alcançados. Entrei para o grupo como uma brincadeira, no começo não 
acreditava que vocês todos poderiam me ajudar a fazer uma escolha tão difícil. Mas vocês conseguiram".

Rodrigo: "A princípio, quando optei por fazer parte do grupo, não esperava que este poderia ser tão útil para ajudar-me em minhas escolhas, uma vez que eu já havia feito outro tipo de orientação que havia me ajudado bastante".

Camila: "Bom, mudou muito desde a primeira vez, o que mais senti diferença foi que eu não esperava que fosse desse jeito, de nós discutirmos e debatermos os assuntos, de falar a nossa opinião, que achamos e se concordamos, achei muito legal e interessante o trabalho assim (...) na minha opinião, acho que o curso [orientação] foi ótimo, as psicólogas foram muito atenciosas, e souberam ouvir nossas opiniões".

\section{CONSIDERAÇÕES ACERCA DOS RESULTADOS OBTIDOS POR MEIO DA ESTRATÉGIA DE RELATOS ESCRITOS EM ORIENTAÇÃO PROFISSIONAL}

A proposta de utilização dos relatos escritos, a partir de proposições que desencadeiem uma auto-avaliação dos orientandos nos momentos inicial e final do processo de Orientação Profissional, mostrou-se de grande relevância na compreensão da condição vivida pelos adolescentes em tais momentos. Tal compreensão, apoiada na função avaliativa dos relatos, auxilia na busca por uma maior efetividade do programa, uma vez que viabiliza um redirecionamento da intervenção de forma compatível com as necessidades de cada grupo.

A dupla função dos relatos, de instrumento de avaliação inicial ou final e fonte de dados para a intervenção(Soares, 1987; Moura, 2001), permitiu, assim, o levantamento de informações relevantes acerca dos adolescentes participantes e muitas delas corroboram os aspectos apontados pela literatura da área, como vivências e sentimentos comuns dos adolescentes em processo de decisão profissional (Levenfus \& Nunes, 2002; Oliveira \& Chakur, 1997).
O uso dos relatos na condição inicial permite identificar os aspectos do processo de tomada de decisão que necessitam ser melhor explorados na orientação. Tais aspectos podem dizer respeito aos déficits de repertório de análise apresentados pelos adolescentes (falta de informação, habilidades pobres de resolução de problemas), ou às concepções preestabelecidas e/ou distorcidas a serem refinadas ou reformuladas (idealizações e estereótipos, aspectos "bons e maus" das diversas influências).

Na presente pesquisa, embora os relatos iniciais propusessem exposição de dificuldades, expectativas e história relacionada à escolha profissional, a análise realizada apontou uma maior ênfase dos adolescentes nas dificuldades sentidas. Os relatos evidenciaram como principais dificuldades os estados de dúvida, insegurança, medo e uma falta generalizada de informações a respeito das profissões e de autoconhecimento. Tais estados configuram uma condição de conflito que dificulta a discriminação das áreas de maior déficit a ser suprido pela orientação. Mesmo os adolescentes que foram mais específicos em suas colocações - conseguindo identificar áreas a serem melhor investigadas, quanto às profissões ou relativas ao autoconhecimento, ao reduzido número de informações, ou à falta de clareza sobre o que considerar (por exemplo, para avaliar uma possível "identificação" com o curso) - retratam o mesmo estado de dúvida e insegurança.

Observa-se também no conjunto dos relatos que a idealização profissional ainda predomina. Embora as experiências e as concepções infantis sejam avaliadas pelos adolescentes como "algo abandonado", o que constitui um sinal de maturidade para a escolha, tem-se ainda a presença de estereótipos sobre os cursos e profissões. Tais estereótipos influenciam indiretamente a escolha e nem sempre o adolescente tem o discernimento necessário para avaliar realisticamente as profissões consideradas.

Outra influência que aparece de forma relevante na condição inicial é a parental. $\mathrm{Na}$ amostra analisada tal influência na escolha da 
profissão foi avaliada positivamente. Os adolescentes reconheceram apoio e incentivo na figura dos pais, os quais valorizariam a autonomia na escolha e a realização profissional do filho. Neste sentido, opiniões ou sugestões dos pais não adquirem caráter coercitivo na opinião dos adolescentes, que se sentem "livres" para realizar suas escolhas, apesar de que tais opiniões, atestaram alguns deles, estariam aumentando suas dúvidas.

Enquanto orientadores, não podemos esquecer que a família sempre exerce uma grande influência na escolha profissional do jovem pois, como destaca Soares (2002), os conceitos e preconceitos da família são passados ao jovem mesmo que ele não queira e isso pesa na hora da escolha. Pais influenciam por meio do modo como falam das profissões, do modo como valorizam uma determinada atividade. Deixar "livre" portanto não significa, a priori, nem ausência de influência e nem apoio a decisão independente. Esta atitude pode contribuir para a condição de dúvida e conflito do adolescente que, sem os importantes feedbacks dos pais, não consegue refinar seus critérios de escolha, aspecto esse a ser trabalhado na orientação.

A pesquisa mostrou também que a utilização dos relatos escritos na condição pós-orientação acrescenta dados importantes para a avaliação do processo e do programa. A análise do conteúdo dos relatos permitiu uma visão mais qualitativa do processo de aprendizagem ocorrido, com a identificação dos aspectos e vivências mais significativos para cada adolescente. Neste sentido, destacam-se o aumento do autoconhecimento e a ampliação das informações sobre a realidade profissional como os aspectos mais enfatizados pelos adolescentes de ambos os grupos, quanto à significância destes repertórios para a escolha.

Neste ponto, os relatos permitiram o acesso aos componentes do programa que pareceram mais efetivos, dada a significância atribuída pelos participantes. Dentre as estratégias utilizadas com o propósito de trabalhar o autoconhe- cimento e o conhecimento da realidade profissional, os adolescentes enfatizaram, respectivamente, o "Exercício Combinado de AutoConhecimento" (Moura, 2001) e a "Entrevista com os Profissionais" (roteiro original - Vasconcellos, Oliveira e Carvalho, 1976; roteiro adaptado - Moura, 2001) como de relevância para o processo de análise das opções e tomada de decisão.

A aprendizagem do processo de tomada de decisão e realização da escolha foram outros aspectos citados com ênfase pelos adolescentes. Eles relatam aumento na capacidade de realização de análises mais criteriosas, a partir da integração das informações obtidas, e atribuem às discussões e reflexões realizadas nos grupos um importante papel na dissolução de dúvidas, medos, e no refinamento destes critérios, levando-os a fazer uma escolha com maior segurança. A experiência de participação em um grupo de orientação foi avaliada positivamente pelos adolescentes, que vislumbraram este aprendizado, o de tomada de decisões, como extensivo a outras áreas da vida.

Assim, parece evidente a riqueza de informações obtidas a partir dos relatos escritos, as quais revelam a dupla funcionalidade anteriormente referida e atribuída ao uso desta estratégia em Orientação Profissional. Os aspectos e vivências mais significativos apontados pelos adolescentes, embora partissem de um tema referencial comum, manifestaram as idiossincrasias decorrentes das histórias individuais, o que certamente muito acrescenta ao orientador na condução do programa. Interessante, também, observar a homogeneidade dentro desta heterogeneidade, o que nos permite generalizar, com cautela, alguns resultados aqui obtidos para a população que procura por orientação. E, com certeza, nos permite também "generalizar" nossos ganhos com o uso da estratégia apresentada para a "população" de orientadores ávidos por um melhor desempenho profissional. 


\section{REFERÊNCIAS BIBLIOGRÁFICAS}

AMATUZZI, M. M. (1996). Apontamentos acerca da pesquisa fenomenológica. Estudos de Psicologia. 13 (1), 5-10.

GIACAGLIA, L. R. (2000). As Atividades para Orientação Vocacional. São Paulo: Pioneira Educação.

LEVENFUS, R. S. (2002). O uso da autobiografia na orientação vocacional. In: Levenfus, R. S. \& Soares, D. H. P. (Orgs.). Orientação vocacional ocupacional: novos achados teóricos, técnicos e instrumentais para a clínica, a escola e a empresa. Porto Alegre: Artmed.

LEVENFUS, R. S. \& Nunes, M. L. T. (2002). Principais temas abordados por jovens centrados na escolha profissional. In: Levenfus, R. S. \& Soares, D. H. P. (Orgs.). Orientação vocacional ocupacional: novos achados teóricos, técnicos e instrumentais para a clínica, a escola e a empresa. Porto Alegre: Artmed.

LUCCHIARI, D. H. P. S. (Org.) (1993). Pensando e Vivendo a Orientação Profissional. São Paulo: Summus.

MAGALHÃES, M. O. (2002). O uso de histórias de vida na orientação de carreira: um enfoque construtivista. In: Levenfus, R. S. \& Soares, D. H. P. (Orgs.). Orientação vocacional ocupacional: novos achados teóricos, técnicos e instrumentais para a clínica, a escola e a empresa. Porto Alegre: Artmed.
MOURA, C. B. (2001). Orientação profissional sob o enfoque da Análise do Comportamento. Londrina: Editora da UEL.

OAKLANDER, V. (1980). Descobrindo crianças: abordagem gestáltica com crianças e adolescentes. São Paulo: Summus.

OLIVEIRA, M. B. L. \& Chakur, G. S. R. (1997). A escolha profissional: necessidades e aspirações dos jovens concluintes do $2^{\circ} \mathrm{grau}$. In: Simpósio Brasileiro de Orientadores Profissionais, 3, Canoas. Anais... Canoas: ULBRA.

OLIVEIRA, M. B. L.; Chakur, G. S. R. \& Momma, A. M. (1997). Desenvolvimento de técnicas grupais: socializando o atendimento. In: Simpósio Brasileiro de Orientadores Profissionais, 3, Canoas. Anais... Canoas: ULBRA.

POLSTER, E. (1987). Every person's life is worth a novel. Nova York: Norton \& Co.

SOARES, D. H. P. (1987). O Joveme a Escolha Profissional. Porto Alegre: Mercado Aberto.

. (2002). A melhor escolha para o momento. Jornal Hoje em Dia, Belo Horizonte, 12 maio.

VASCONCELLOS, M. J. E.; Oliveira, A. L. Q. \& Carvalho, M. A. V. (1976). Curso de Informação Profissional. Belo Horizonte: Vigília; Rio de Janeiro: FENAME.

WHITE, M.; Epston, D. (1990). Narrative means to therapeutic ends. New York: Norton.

Recebido para publicação em 12 de fevereiro de 2003 e aceito em 25 de setembro de 2003. 